\title{
An investigation of saliva and plasma levels of urotensin 2 in recently diagnosed type 2 diabetes mellitus patients on metformin treatment
}

\author{
Nevzat Gozel', Kubra Oral', Fethi Ahmet Ozdemir², Erhan Onalan', Tuncay Kuloglu³, Suleyman Aydın', \\ Ahmet Karataş5, Faruk Kılınç \\ ${ }^{1}$ Department of Internal Medicine, Faculty of Medicine, Firat University, Elazig, Turkey \\ ${ }^{2}$ Department of Molecular Biology and Genetics, Faculty of Science and Art, Bingol University, Bingol, Turkey \\ ${ }^{3}$ Deparment of Histology, Faculty of Medicine, Firat University, Elazig, Turkey \\ ${ }^{4}$ Department of Biochemistry, Faculty of Medicine, Firat University, Elazig, Turkey \\ ${ }^{5}$ Department of Rheumatology, Faculty of Medicine, Firat University, Elazig, Turkey \\ ${ }^{6}$ Department of Endocrinology, Faculty of Medicine, Firat University, Elazig, Turkey
}

\begin{abstract}
Introduction: Diabetes mellitus $(\mathrm{DM})$ is a primary disease of the carbohydrate metabolism that is characterised by absolute or relative insulin deficiency, or insulin resistance. Although life expectancy is low for diabetic patients, the prognosis has been improved in recent decades. Metformin is an oral antidiabetic that reduces insulin resistance and plasma glucose levels by decreasing glucose production in the liver. It can be used as a standalone treatment or in combination with other antidiabetic medications or insulin. Urotensin 2 (U-II), which is one of the most effective known vasoconstrictor peptides, was observed to act as a vasoconstrictor in diseases such as hypertension and heart failure, and to induce vasodilation in healthy volunteers. Some studies have proposed that the activation of the U-II system could lead to metabolic syndrome. Certain studies have determined a link between DM and U-II. However, there exist no studies on the effects of U-II in recently diagnosed type 2 DM patients after metformin treatment.

This study aims to investigate the plasma and saliva levels of U-II at diagnosis and after a three-month metformin treatment in recently diagnosed type $2 \mathrm{DM}$ patients, and to compare these levels to those of healthy volunteers.

Material and methods: Our study compared 30 recently diagnosed type 2 DM patients to their states after three-month metformin treatment and 30 healthy volunteers.

Results: When compared with the control group, there was no significant increase in the plasma and saliva U-II levels of recently diagnosed type $2 \mathrm{DM}$ patients. We determined a statistically significant increase in the plasma and saliva ureotensin-2 levels of recently diagnosed type $2 \mathrm{DM}$ patients after a three-month metformin treatment $(\mathrm{p}<0.05)$

Conclusions: It was concluded that the patients with type 2 DM have a multifactorial aetiopathogenesis and an increase in U-II levels after metformin treatment. Metformin has no known effect on the U-II metabolism; therefore, the findings need confirmation through more clinical and experimental studies with more participants. (Endokrynol Pol 2020; 71 (3): 249-255)
\end{abstract}

Key words: type 2 diabetes mellitus; metformin; urotensin 2

\section{Introduction}

Type 2 diabetes mellitus (DM) is a primary disorder of the carbohydrate mechanism, which has chronic progression, a multifactorial aetiopathogenesis, is characterised by absolute or relative insulin deficiency or insulin resistance, presents with high plasma glucose levels as the primary symptom, demonstrates significant changes in lipid and protein metabolisms, and displays a heterogeneous clinical picture [1,2].

Besides its acute complications, DM progresses with chronic complications such as retinopathy, which causes vision loss in the long term; nephropathy and vascular diseases, which cause renal failure; neuropathy, which ultimately results in the amputation of the foot; and additionally, with autonomous neuropathy, which can lead to cardiovascular, genitourinary, gastrointestinal system disorders; and sexual function disorders; and poses a high morbidity and early mortality risk $[3,4]$.

The prevalence of DM has been gradually increasing. The International Diabetes Federation (IDF) predicts that the number of diabetic patients, which was 425 million in 2017, will reach 629 million by 2045. According to International Diabetes Federation (IDF) data, it is estimated that 4 million people between the ages of 20 and 79 years died because of diabetes in 2017 [5]. 
Urotensin 2 (U-II) is one of the strongest known vasoconstrictor peptides, and it is even stronger than endothelin-1, which is renowned for its vasoconstrictor properties. U-II is a peptide that is made up of 11 amino acids. The U-II molecule was first detected in the spinal cord of fish. It contains peptide sequences that resemble somatostatin. The U-II peptide arises from the prepro-U-II molecule, which is a large precursor molecule. Plasma urotensin levels were found to be elevated in renal failure, diabetes, hypertension, congestive heart failure, and portal hypertension. While U-II acts as a vasoconstrictor in diseases such as hypertension and heart failure, it was seen to induce vasodilation in healthy volunteers [6-9]. Urine and plasma U-II levels of type 2 diabetic patients were found to be higher in those with disrupted renal function than in those with normal renal function [10]. Tubular epithelial cells obtained from the nephrectomy of patients with diabetic nephropathy showed an overexpression of U-II and the urotensin receptor [11]. U-II was shown to activate "nicotinamide adenine dinucleotide phosphate oxidase" in vascular muscle cells. Oxidative stress, which is elevated by this pathway, was proposed to contribute significantly to the development of diabetic retinopathy [12-14]. Recent studies have demonstrated that U-II can be used as a biomarker in type $2 \mathrm{DM}$ patients with diabetic nephropathy and atherosclerosis and rheumatic valvular disease [15]. In the present study, we investigate the relationship of plasma and saliva levels of U-II with type 2 DM.

\section{Material and methods}

\section{Participants}

Prior to the study, ethical approval was obtained from Firat University Non-Invasive Research Ethics Committee Directorate (Date: 30.03.2017, Approval number: 06/45). This study included: 30 patients who presented to the Internal Diseases polyclinic and received a diagnosis of type $2 \mathrm{DM}$, and started metformin treatment following the diagnosis; and 30 healthy volunteers who presented to our polyclinic for a general check-up and were found to have no diseases. Individuals who were diagnosed with diabetes and who previously had hypertension, any known cardiovascular diseases, a history of malignancy, an infection, acute/chronic kidney failure, acute/chronic liver disease, a history of steroid use, a history of immunosuppressive medication use, were pregnant, or experienced communication difficulties related to sociocultural competence were excluded from the study. The demographic data (age and sex) of the entire study group were recorded from patient files. Diagnosis of diabetes was based on the following criteria: fasting plasma glucose $\geq 126 \mathrm{mg} / \mathrm{dL}$, two-hour glucose level $\geq 200 \mathrm{mg} / \mathrm{dL}$ in 75-gram glucose tolerance test, and $\mathrm{HbA}_{1 \mathrm{c}} \geq 6.5 \%$.

\section{Samples}

Besides fasting plasma glucose, the following metabolic parameters were determined for both the study group and the control group: serum lipid levels (total cholesterol, LDL, triglyceride), liver and kidney function tests (ALT, AST, urea, creatinine), and haemogram values. For the study group, postprandial plasma glucose and
$\mathrm{HbA}_{1 \mathrm{c}}$ levels were also investigated in order to better evaluate the glycaemic states. Both the healthy control group and the patients provided $4 \mathrm{ml}$ blood samples from the left antecubital region and $4 \mathrm{ml}$ saliva at the initial presentation, and these were collected in tubes with a protease inhibitor (aprotinin). Blood samples were placed into EDTA tubes, lightly shaken, and promptly transported to the biochemistry laboratory on ice blocks. These samples were centrifuged at $3500 \mathrm{rpm}$ for $10 \mathrm{~min}$. They were then transferred to Eppendorf tubes and stored at $-20^{\circ} \mathrm{C}$ until retrieved for the assay. Saliva samples were also collected into aprotinin tubes, centrifuged by the same method, and stored at $-20^{\circ} \mathrm{C}$ until retrieved for the assay. U-II (U-II/UCN2) levels (Human U-II/UCN2; catalogue no: 20112-5285 Sunred Biological Technology Co., Ltd, Shanghai, CHINA) of the serum and saliva samples were determined with the Elisa method in accordance with the assay procedures described in the kit catalogue. The human UCN2 ELISA kit had a measurement range of $0.1-15 \mathrm{pmol} / \mathrm{L}$, an intra-assay CV value $<10 \%$, an inter-assay CV value $<12 \%$, and a sensitivity of $0.055 \mathrm{pmol} / \mathrm{L}$. Plate washing was performed using the automatic microplate washer Bio-Tek ELX50 (BioTek Instruments, USA) and absorbance readings were taken using the ChroMate, Microplate Reader P4300 (Awareness Technology Instruments, USA) device. Test results were presented in pmol/L. The measurement of U-II in saliva samples by the U-II kit was assessed according to the procedure published by Aydin, and the kit was determined to measure U-II in saliva samples as well [16].

\section{Immunohistochemistry}

For U-II immunoreactivity, the submandibular and parotid salivary glands were used. Five- to six-millimetre sections obtained from paraffin blocks were mounted onto polylysine slides. After being deparaffinised, the tissues were passed through alcohol series and boiled $7+5 \mathrm{~min}$. in citrate buffer solution at $\mathrm{pH} 6$ in a microwave oven $(750 \mathrm{~W})$ for antigen retrieval. After boiling, they were cooled at room temperature for $20 \mathrm{~min}$., washed with PBS (Phosphate Buffered Saline, P4417, Sigma-Aldrich, USA) for $3 \times 5$ min., and incubated with hydrogen peroxide blocking solution for $5 \mathrm{~min}$. in order to prevent endogenous peroxidase activity (Hydrogen Peroxide Block, TA-125-HP, Lab Vision Corporation, USA). After washing the tissues with PBS for $3 \times 5$ min., Ultra V Block solution (TA-125-UB, Lab Vision Corporation, USA) was applied onto the tissues for $5 \mathrm{~min}$. to prevent non-specific background staining, and they were incubated with the primary antibody (urotensin II antibody, sc-52300, Santa Cruz Biotechnology, California, USA), which was diluted at 1:200 for $60 \mathrm{~min}$. at room temperature in a humid environment. After the primary antibody application, the tissues were washed with PBS for $3 \times 5 \mathrm{~min}$. and incubated with the secondary antibody (biotinylated Goat Anti-Polyvalent [antimouse / rabbit IgG], TP-125-BN, Lab Vision Corporation, USA) for $30 \mathrm{~min}$. at room temperature in a humid environment. After the secondary antibody application, the tissues were washed with PBS for $3 \times 5 \mathrm{~min}$. and incubated with streptavidin peroxidase (TS-125-HR Lab Vision Corporation, USA) for $30 \mathrm{~min}$. at room temperature in a humid environment and transferred into PBS. The 3-amino-9-ethylcarbazole (AEC) substrate + AEC chromogen (AEC Substrate, TA-015 and HAS, AEC Chromogen, TA-002-HAC, Lab Vision Corporation, USA) solution was dropped onto the tissues, and they were simultaneously washed with PBS once an image signal was acquired under the light microscope. The tissues were counterstained with Mayer's haematoxylin and covered with the appropriate mounting solution (Large Volume Vision Mount, TA-125-UG, Lab Vision Corporation, USA) after being passed through PBS and distilled water. The preparates were evaluated and photographed using a Leica DM500 microscope (Leica DFC295).

\section{Statistical analysis}

All analyses were performed using the Statistical Package for the Social Sciences (SPSS) software version 22.0 (SPSS Inc., Chicago, USA). The data were analysed using descriptive statistical meth- 
ods, Student's t-test, equivalents, and variance analysis. This study considered $p<0.05$ as the threshold for statistical significance.

\section{Results}

The clinical, demographic, and laboratory data of the individuals included in the study are summarised in Table 1.

The diabetic patient group had a higher mean age than the healthy control group, with statistical significance $(p<0.001)$. The diabetic group manifested an even distribution of female and male patients, while most of the individuals that comprised the healthy control group were males. Fasting blood sugar levels were higher in the diabetic group, as expected ( $p<0.001$ ). No difference was determined between the groups in terms of liver function tests. Low-density lipoprotein levels (LDL) of the diabetic patients were significantly higher than those of the healthy controls at the time of diagnosis (respectively, $124.2 \pm 31.9 ; 152.03 \pm 51.3$; $\mathrm{p}=0.01$ ); however, this difference between the two groups disappeared after the blood sugar levels of diabetics were regulated by the three-month treatment (respectively, 124.2 \pm 31.9; $127.9 \pm 33.6 ; \mathrm{p}=0.67$ ).

Plasma U-II levels of the healthy control group, the type $2 \mathrm{DM}$ group at diagnosis, and the DM group after a three-month treatment were measured as $4.38 \pm 2.8$, $4.45 \pm 2.57$, and $5.9 \pm 3.27 \mathrm{pmol} / \mathrm{L}$, respectively. A com- parison of the plasma U-II levels of the DM group after a three-month treatment with healthy controls revealed significantly higher U-II levels in the DM group after treatment $(\mathrm{p}=0.015)$.

Saliva U-II levels of the healthy control group, the type $2 \mathrm{DM}$ group at diagnosis, and the DM group after 3-month treatment were measured as $4.58 \pm 1.96$, $4.69 \pm 1.46$, and $5.37 \pm 1.94 \mathrm{pmol} / \mathrm{L}$, respectively. Although there were numerical differences between the groups with regard to saliva U-II levels, no statistical differences were determined.

The light microscopic evaluation of the immunohistochemical staining performed for U-II immunoreactivity revealed U-II immunoreactivity in the intralobular and interlobular ducts in the submandibular (Fig. 1a) and parotid (Fig. 1b) glands. This data indicated that U-II was expressed in salivary glands.

\section{Discussion}

The peptide molecule U-II is one of the strongest known vasoconstrictor peptides. It was seen to act as a vasoconstrictor in diseases such as hypertension and heart failure, while it induces vasodilation in healthy volunteers, and its plasma levels were found to be elevated in renal failure, diabetes, hypertension, congestive heart failure, and portal hypertension. Studies have shown

Table 1. Clinical, demographic, and laboratory data of the groups included in the study

\begin{tabular}{|c|c|c|c|c|c|c|}
\hline & $\begin{array}{l}\text { Control } \\
(n=30)\end{array}$ & $\begin{array}{l}\text { DM 0. month } \\
\quad(n=30)\end{array}$ & $\begin{array}{l}\text { DM 3. month } \\
\quad(n=30)\end{array}$ & P1 & $\mathbf{P 2}$ & P3 \\
\hline Age [years] & $30.10 \pm 8.8$ & $54.63 \pm 10.8$ & $54.63 \pm 10.8$ & $<0.001$ & $<0.001$ & $>0.05$ \\
\hline Gender [Male/Female] & $2 / 28$ & $17 / 13$ & $17 / 13$ & - & - & - \\
\hline $\mathrm{FPG}[\mathrm{mg} / \mathrm{dL}]$ & $89.9 \pm 10.7$ & $178.3 \pm 47.10$ & $136.10 \pm 39.3$ & $<0.001$ & $<0.001$ & $<0.001$ \\
\hline $\mathrm{PPG}[\mathrm{mg} / \mathrm{dL}]$ & & $287 \pm 84.9$ & $217.17 \pm 77.28$ & - & - & $<0.001$ \\
\hline AST [U/L] & $20.9 \pm 11.06$ & $23.3 \pm 13.2$ & $21.40 \pm 8.93$ & 0.45 & 0.09 & 0.22 \\
\hline ALT [UL] & $22.6 \pm 14.10$ & $29.4 \pm 17.8$ & $21.90 \pm 13.09$ & 0.10 & 0.82 & 0.084 \\
\hline Urea [mg/dL] & $25.07 \pm 7.9$ & $29.47 \pm 8.1$ & $31.37 \pm 10.73$ & 0.03 & 0.01 & 0.144 \\
\hline Creatinine [mg/dL] & $0.67 \pm 0.16$ & $0.75 \pm 0.24$ & $0.75 \pm 0.23$ & 0.18 & 0.17 & 0.973 \\
\hline Haemoglobin & $12.7 \pm 1.5$ & $14.2 \pm 1.78$ & $14.11 \pm 1.81$ & $<0.01$ & $<0.01$ & $>0.05$ \\
\hline Haematocrit & $39.2 \pm 3.85$ & $43 \pm 5.2$ & $42.3 \pm 4.95$ & 0.001 & 0.008 & 0.310 \\
\hline LDL-C [mg/dL] & $124.2 \pm 31.90$ & $152.03 \pm 51.3$ & $127.9 \pm 33.6$ & 0.01 & 0.67 & 0.025 \\
\hline Triglyceride [mg/dL] & $204.8 \pm 80.126$ & $255.9 \pm 150.78$ & $208.9 \pm 84.2$ & 0.10 & 0.84 & 0.04 \\
\hline $\operatorname{HBA}_{1 \mathrm{c}}(\%)$ & & $7.5 \pm 1.6$ & $6.2 \pm 1.2$ & - & - & $<0.001$ \\
\hline UT-II blood [pmol/L] & $4.38 \pm 2.8$ & $4.45 \pm 2.57$ & $5.9 \pm 3.27$ & 0.59 & 0.17 & 0.015 \\
\hline UT-II saliva [pmol/L] & $4.58 \pm 1.96$ & $4.69 \pm 1.46$ & $5.37 \pm 1.94$ & 0.814 & 0.12 & 0.060 \\
\hline
\end{tabular}

P1 — control with DM-0. month comparison; P2 — control with DM-3. months comparison; P3 - DM-0. months with DM-3. months comparison; FPG — fasting plasma glucose; PPG — postprandial blood glucose; AST — aspartate aminotransferase; ALT — alanine aminotransferase; LDL-C — low density lipoprotein cholesterol; $\mathrm{HBA}_{1 \mathrm{c}}$ - haemoglobin $\mathrm{A}_{1 \mathrm{c}} ; \mathrm{UT}$-II — urotensin-2 


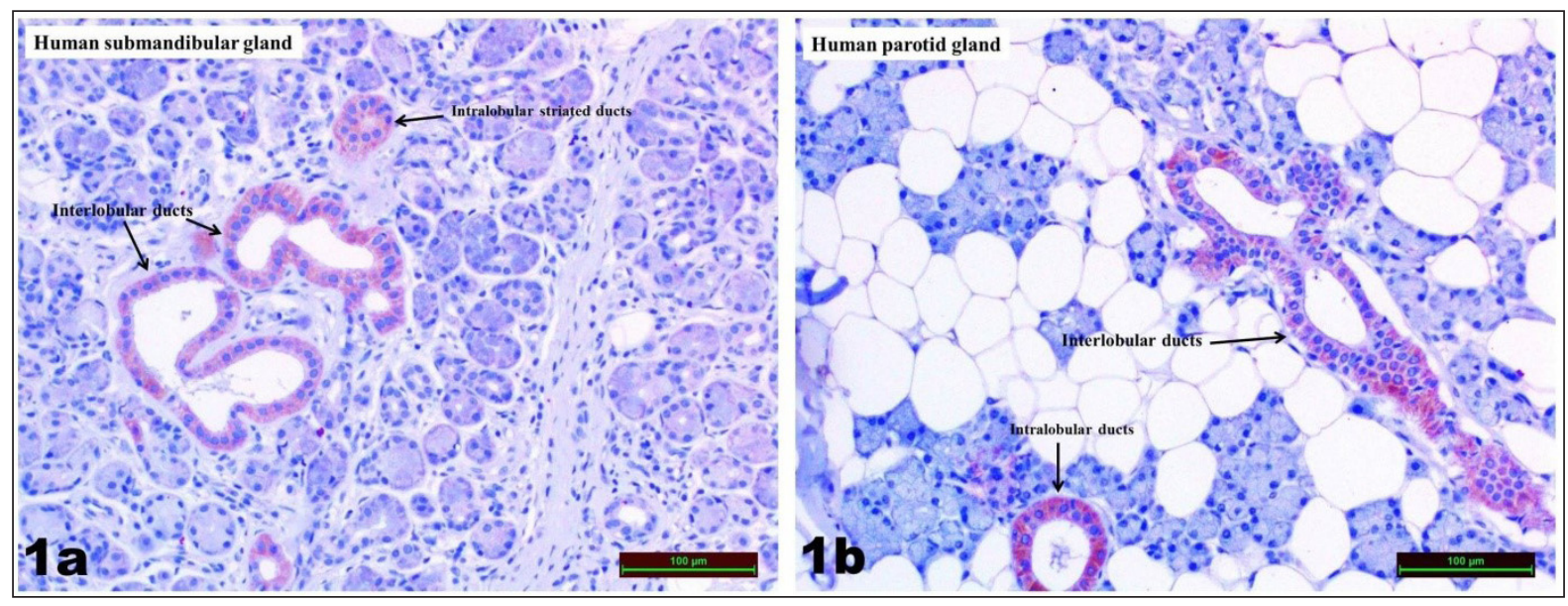

Figure 1. Urotensin 2 immunoreactivity; intralobular ducts and interlobular ducts in the submandibular (1a) and parotid (1b) glands

that, in the heart, urotensin leads to reflex tachycardia, fibrosis, coronary vasoconstriction, and hypertrophy of the heart muscle [17-20].

The prevalence of DM, which is a chronic disease, has been increasing rapidly. Diabetes mellitus-related acute and chronic complications have a strong impact on life quality, morbidity, and mortality. However, the pathogenesis of type $2 \mathrm{DM}$ causes of the associated complications and the involved factors have not yet been fully discovered and are still being contended.

There are limited studies that have investigated how the U-II molecule is affected in recently diagnosed patients on metformin. In this study, we researched how the plasma and saliva levels of the U-II molecule are altered in recently diagnosed type 2 DM patients, before and after three months of metformin treatment.

The present study is the first that has investigated this matter. We compared patients diagnosed with type $2 \mathrm{DM}$ before and after three months of metformin treatment with healthy volunteers who had no history of any diseases or medication use. Across these groups, we determined a progressive numerical increase in U-II levels from the healthy control group to recently diagnosed type 2 DM patients, and diabetic patients after three months of treatment. However, this increase was only statistically significant between the plasma U-II levels of the healthy control group and the three-month metformin treatment group. Saliva U-II levels demonstrated a similar progressive increase, but these differences were not statistically significant.

Nazer et al. [21] compared patients on metformin to those who were not, in terms of their alanine aminotransferase, aspartate aminotransferase, lactate dehydrogenase, and total bilirubin levels before and after a coronary artery bypass graft, and determined a significant decrease in those who used metformin. In this sense, the present data are not in accordance with our study. In our study, the alanine aminotransferase and aspartate aminotransferase levels of type $2 \mathrm{DM}$ patients were not significantly different before and after three months of metformin treatment. In this regard, these results can be interpreted as U-II levels having no effect on liver function tests.

In a study conducted by Anushiravani et al. [22], which included 150 patients, no statistically significant differences were found between the metformin group and the placebo group in terms of their alanine aminotransferase and aspartate aminotransferase enzymes. In this regard, these results were congruent with our findings. Therefore, it can be stated that metformin use does not have a hepatotoxic effect on the liver and does not have an effect on liver function tests in patients with normal liver function tests.

In a study that included 60 patients diagnosed with polycystic ovary [23], Shaker et al. determined an increase in HDL-cholesterol levels, and a significant decrease in the total cholesterol/HDL-cholesterol ratio in blood tests done after three months of metformin treatment. Meanwhile, our study determined a statistically significant decrease in blood LDL and triglyceride levels of recently diagnosed type $2 \mathrm{DM}$ patients after a three-month metformin treatment, and accordingly, metformin use was determined to have favourable effects on DM patients with high LDL and triglyceride levels. This positive difference might have appeared directly due to metformin or through the regulation of blood sugar.

In a study by Totsune et al. [24], which included 48 patients diagnosed with type $2 \mathrm{DM}$ and 10 healthy volunteers, the patients were assigned to three groups based on their renal function tests. According to their classification, the first group had a creatinine clearance rate $(\mathrm{Ccr}) \geq 70 \mathrm{~mL} / \mathrm{min}$., the second group had a $30 \leq \mathrm{Ccr}<70 \mathrm{~mL} / \mathrm{min}$., and the third group had 
a Ccr $<30 \mathrm{~mL} / \mathrm{min}$. Compared to the control group, patients diagnosed with DM had significantly elevated U-II levels, and the highest levels were determined in the third group. As the severity of the renal function disorder increases, U-II levels show a progressive increase, suggesting that there is a cause-effect relationship between U-II and the development of renal failure. In our study, all groups had normal kidney function; therefore, we were not able to make such a comparison.

In our study, no statistically significant differences were determined between the control group and the recently diagnosed type $2 \mathrm{DM}$ patients with regard to the plasma and saliva levels of U-II. This can be explained by the fact that the blood samples obtained from our patients corresponded to the early stages of the type $2 \mathrm{DM}$ diagnosis and that they were obtained before blood sugar levels and $\mathrm{HbA}_{1 \mathrm{c}}$ reached much higher levels, and, accordingly, before the development of microvascular and macrovascular damage. In this regard, the earlier that diabetic patients are diagnosed and the earlier that glycaemic control is established with early treatment, the more effectively the complications associated with DM will be prevented. On the other hand, when we investigated the plasma and saliva U-II levels of these recently diagnosed type $2 \mathrm{DM}$ patients after three months of metformin treatment, we determined a statistically significant increase in plasma U-II levels and a numerical but insignificant increase in saliva levels. This difference between plasma and saliva levels could be caused by the presence of different enzymes and secretions in the saliva. These increases can be linked to the length of time since diagnosis.

In a study conducted by Calan et al. [25] that compared 42 patients diagnosed with gestational DM and 42 body mass index- and age-matched controls without gestational DM, U-II levels were determined to be significantly higher in those with gestational DM. The authors connected the rise in the U-II levels of gestational DM patients to insulin resistance, high body mass index, and high blood glucose levels. In this regard, their results are in accordance with our results numerically, but not statistically. This can be explained by the exclusion of pregnant patients from our study, because our patients did not demonstrate pregnancy-related changes in the vascular structures.

Hursitoglu et al. [26] compared 21 women diagnosed with gestational DM, 15 pregnant women without a DM diagnosis, and 22 age-matched, non-pregnant women. U-II levels were found to be significantly higher in pregnant women with and without gestational DM compared to non-pregnant women. No statistically significant difference was found between pregnant women with gestational DM and those without gestational DM. In the group not diagnosed with gestational
DM, U-II levels were found to be significantly lower after pregnancy. In terms of diabetes, the results of this study are similar to our results because the potential relationship between U-II and DM is known. In our study, there was no statistically significant difference between those with type $2 \mathrm{DM}$ and those without DM in terms of plasma and saliva U-II levels. This can be because the complications associated with DM had not yet developed and glycaemic control was established by the early diagnosis and treatment of the patients. Therefore, early diagnosis, treatment, and screening are of great importance in preventing the development of disease-related complications in DM. Although our patients were not cases of gestational DM, the results are similar regarding DM and suggest that there can be a cause-effect relationship between U-II levels and DM.

Tabur et al. [27] compared 23 patients with concomitant DM and microalbuminuria, 23 normoalbuminuric patients with DM, and 25 healthy controls. Compared with the normoalbuminuric and healthy groups, the microalbuminuric group showed significantly higher U-II levels. In turn, the normoalbuminuric patient group showed significantly higher U-II levels compared to the control group. These results also support the potential relationship between DM and U-II. The authors [27] reasoned, based on these findings, that the U-II molecule could be involved in the development of diabetic nephropathy. In our study, there was not a significant difference between the two groups. In this regard, our study is not in accordance with the study conducted by Tabur et al. This can be due to the absence of nephropathy symptoms in our type $2 \mathrm{DM}$ patients and the establishment of glycaemic control before the appearance of DM-related complications through early diagnosis and treatment.

A study done by Gruson et al. [28] included 360 patients diagnosed with type $2 \mathrm{DM}, 294$ patients diagnosed with metabolic syndrome, and 66 patients without metabolic syndrome, in different groups. Urotensin 2 levels were found to be higher in diabetic patients with a diagnosis of metabolic syndrome than in those without metabolic syndrome.

In our study, the subjects were evaluated in three categories as healthy volunteers, recently diagnosed type $2 \mathrm{DM}$ patients, and type $2 \mathrm{DM}$ patients after three months of metformin treatment. Blood and saliva U-II levels were not statistically different between the control group and the recently diagnosed type $2 \mathrm{DM}$ patients. This can be because the grouping criteria we applied to our patient population were different than those used by Gruson et al. [28] and the groups were recruited from different populations.

In a study by Siddharta et al. [29], the urotensin receptor antagonist palosuran was administered to 
type 2 DM patients, who were followed-up with dietary guidance for four weeks, and they determined no changes in insulin secretion, insulin sensitivity, and daily blood glucose levels when compared to the placebo group. In this regard, certain aspects of this study are in accordance with the present study. In the present study, there were no statistically significant differences between the U-II levels of the control group and the recently diagnosed DM group. This can be explained by U-II levels increasing due to the renal damage and micro- and macrovascular damage associated with the complications of DM rather than being a factor that triggers the development of this disease. The other comparison, between the healthy group and the recently diagnosed group after three months of metformin treatment, determined a numerical increase that did not reach statistical significance. Between the states of the recently diagnosed group and this group after three months of metformin treatment, there was a statistically significant increase in the plasma U-II levels and a numerical, yet statistically insignificant, increase in saliva U-II levels. The increase in U-II levels that appeared independently from blood glucose levels in recently diagnosed type $2 \mathrm{DM}$ patients after the establishment of glycaemic control with metformin treatment gave us the impression that metformin influences the U-II metabolism through an unknown pathway or mechanism.

\section{Conclusions}

The results we obtained in this study support the notion that there exists a cause-effect relationship between type $2 \mathrm{DM}$ and blood/saliva levels of U-II (confirming previous studies). Probably, this relationship would become more apparent as the time since diagnosis becomes longer and the DM-related complications become manifest. In this aspect, our study is the first on this matter, and we believe that it will serve as a reference for future studies. The uneven distribution of female and male patients between the healthy group and the patient group, the limited number of patients, and the short patient follow-up time are among the important limitations of our study. Experimental and clinical studies with larger patient series and long-term observations are warranted in order to clearly determine the relationship of U-II with DM and the related complications.

\section{References}

1. Olefsky J. Diabetes mellitus. Cecil Textbook of Medicine. 18th ed. Wynagaarden and Smith Jr, WB Saunders Int 1992: 248-262.

2. Güven T. Diabetes Mellitus'lu Hastalarda Yaşam Kalitesi ve Depresyon Etkisinin Araştırılması Uzmanlık Tezi. TC Sağlık Bakanlığı Şişli Etfal Eğitim ve Arastırma Hastanesi Psikiyatri Kliniği, İstanbul 2007.

3. Göç DM. Diyabetes Mellitus'lu Hastalarda, Hastalığın Süresi, Hastaların Öğrenim Düzeyi, Diyabetik Ayakla İlgili Eğitim Alma Durumu, Metabolik Değerlerin, Diyabetik Ayak Gelişim Riski ve Diyabetik Ayak- dan Koruyucu Davranış Modelleri Geliştirmeye Etkileri. Uzmanlık Tezi. Sağlık Bakanlığı Haydarpaşa Numune Eğitim ve Araştırma Hastanesi, İstanbul 2008.

4. Joslin EP, Kahn CR. Joslin's Diabetes Mellitus. Ronald KC (ed). 14th ed.Ronald KC, Kahn CR. ed. Lippincott Williams \& Wilkins, 2005

5. IDF (International Diabetes Federation). IDF Diabetes Atlas, 8th ed. International Diabetes Federation, Belgium: 2017: 161-163.

6. Tibaldi J. Importance of postprandial glucose levels as a target for glycemic control in type 2 diabetes. South Med J. 2009; 102(1): 60-66, doi: 10.1097/SMJ.0b013e318188898e, indexed in Pubmed: 19077774.

7. Ong KL, Lam KSL, Cheung BMY. Urotensin II: its function in health and its role in disease. Cardiovasc Drugs Ther. 2005; 19(1): 65-75, doi: 10.1007/s10557-005-6899-x, indexed in Pubmed: 15883758.

8. McDonald J, Batuwangala M, Lambert DG. Role of urotensin II and its receptor in health and disease. J Anesth. 2007; 21(3): 378-389, doi: 10.1007/s00540-007-0524-z, indexed in Pubmed: 17680191.

9. Vaudry H, Leprince J, Chatenet D, et al. International Union of Basic and Clinical Pharmacology. XCII. Urotensin II, urotensin II-related peptide, and their receptor: from structure to function. Pharmacol Rev. 2015; 67(1): 214-258, doi: 10.1124/pr.114.009480, indexed in Pubmed: 25535277.

10. Totsune K, Takahashi K, Arihara Z, et al. Increased plasma urotensin II levels in patients with diabetes mellitus. Clin Sci (Lond). 2003; 104(1): 1-5, doi: 10.1042/, indexed in Pubmed: 12519081.

11. Langham RG, Kelly DJ, Gow RM, et al. Increased expression of urotensin II and urotensin II receptor in human diabetic nephropathy. Am J Kidney Dis. 2004; 44(5): 826-831, indexed in Pubmed: 15492948.

12. Djordjevic T, BelAiba RS, Bonello S, et al. Human urotensin II is a novel activator of NADPH oxidase in human pulmonary artery smooth muscle cells. Arterioscler Thromb Vasc Biol. 2005; 25(3): 519-525, doi: 10.1161/01. ATV.0000154279.98244.eb, indexed in Pubmed: 15618545.

13. Baynes JW, Thorpe SR. Role of oxidative stress in diabetic complications: a new perspective on an old paradigm. Diabetes. 1999; 48(1): 1-9, doi: 10.2337/diabetes.48.1.1, indexed in Pubmed: 9892215.

14. El-Remessy AB, Behzadian MA, Abou-Mohamed G, et al. Experimental diabetes causes breakdown of the blood-retina barrier by a mechanism involving tyrosine nitration and increases in expression of vascular endothelial growth factor and urokinase plasminogen activator receptor. Am J Pathol. 2003; 162(6): 1995-2004, doi: 10.1016/S0002-9440(10)64332-5, indexed in Pubmed: 12759255.

15. Suguro T, Watanabe T, Kodate $\mathrm{S}$, et al. Increased plasma urotensin-II levels are associated with diabetic retinopathy and carotid atherosclerosis in Type 2 diabetes. Clin Sci (Lond). 2008; 115(11): 327-334, doi: 10.1042/CS20080014, indexed in Pubmed: 18338983

16. Aydin S. A short history, principles, and types of ELISA, and our laboratory experience with peptide/protein analyses using ELISA. Peptides. 2015; 72: 4-15, doi: 10.1016/j.peptides.2015.04.012, indexed in Pubmed: 25908411.

17. Ong KL, Lam KSL, Cheung BMY. Urotensin II: its function in health and its role in disease. Cardiovasc Drugs Ther. 2005; 19(1): 65-75, doi: 10.1007/s10557-005-6899-x, indexed in Pubmed: 15883758.

18. McDonald J, Batuwangala M, Lambert DG. Role of urotensin II and its receptor in health and disease. J Anesth. 2007; 21(3): 378-389, doi: 10.1007/s00540-007-0524-z, indexed in Pubmed: 17680191.

19. Bousette N, Patel L, Douglas SA, et al. Increased expression of urotensin II and its cognate receptor GPR14 in atherosclerotic lesions of the human aorta. Atherosclerosis. 2004; 176(1): 117-123, doi: 10.1016/j.atherosclerosis.2004.03.023, indexed in Pubmed: 15306183.

20. Ong KL, Lam KSL, Cheung BMY. Urotensin II: its function in health and its role in disease. Cardiovasc Drugs Ther. 2005; 19(1): 65-75, doi: 10.1007/s10557-005-6899-x, indexed in Pubmed: 15883758.

21. Nazer RI, Abalhassan MF, Alburikan KA. Liver enzyme trends in patients taking uninterrupted metformin before and after coronary surgery. Cardiovasc Diagn Ther. 2018; 8(4): 469-479, doi: 10.21037/cdt.2018.05.04, indexed in Pubmed: 30214862.

22. Anushiravani A, Haddadi N, Pourfarmanbar M, et al. Treatment options for nonalcoholic fatty liver disease: a double-blinded randomized placebo-controlled trial. Eur J Gastroenterol Hepatol. 2019; 31(5): 613-617, doi: 10.1097/MEG.0000000000001369, indexed in Pubmed: 30920975.

23. Shaker M, Mashhadani ZI, Mehdi AA. Effect of Treatment with Metformin on Omentin-1, Ghrelin and other Biochemical, Clinical Features in PCOS Patients. Oman Med J. 2010; 25(4): 289-293, doi: 10.5001/omj.2010.84, indexed in Pubmed: 22043360.

24. Totsune K, Takahashi K, Arihara Z, et al. Elevated plasma levels of immunoreactive urotensin II and its increased urinary excretion in patients with Type 2 diabetes mellitus: association with progress of diabetic nephropathy. Peptides. 2004; 25(10): 1809-1814, doi: 10.1016/j. peptides.2004.06.024, indexed in Pubmed: 15476950.

25. Calan M, Arkan T, Kume T, et al. The relationship between urotensin II and insulin resistance in women with gestational diabetes mellitus. Hormones (Athens). 2019; 18(1): 91-97, doi: 10.1007/s42000-018-0084-7, indexed in Pubmed: 30471011. 
26. Hursitoglu M, Ekiz A, Mete F, et al. Plasma Urotensin II concentration in gestational diabetes. Arch Clin Exp Med. 2017; 2: 66-70.

27. Tabur S, Korkmaz H, Eren MA, et al. Urotensin-II level and its association with oxidative stress in early diabetic nephropathy. J Diabetes Complications. 2015; 29(1): 115-119, doi: 10.1016/j.jdiacomp.2014.07.011, indexed in Pubmed: 25179234.

28. Gruson D, Rousseau MF, Ketelslegers JM, et al. Raised plasma urotensin II in type 2 diabetes patients is associated with the meta- bolic syndrome phenotype. J Clin Hypertens (Greenwich). 2010 12(8): 653-660, doi: 10.1111/j.1751-7176.2010.00336.x, indexed in Pubmed: 20695946.

29. Sidharta PN, Rave K, Heinemann L, et al. Effect of the urotensin-II receptor antagonist palosuran on secretion of and sensitivity to insulin in patients with Type 2 diabetes mellitus. Br J Clin Pharmacol. 2009; 68(4): 502-510, doi: 10.1111/j.1365-2125.2009.03480.x, indexed in Pubmed: 19843053 